\title{
Gut
}

Leading article

\section{The ursodeoxycholic acid story in primary biliary cirrhosis}

\begin{abstract}
The name ursodeoxycholic acid (UDCA) is derived from 'ursocholeinische säure' used by Hammarsten in 1902 to describe a bile acid discovered in polar bears. The bile acid he identified was actually chenodeoxycholic acid. ${ }^{1}$ UDCA is the $7 \beta$ epimer of chenodeoxycholic acid and has the chemical structure $3 \alpha$ 7 $\beta$-dihydroxy-5 $\beta$-cholan-24-oic acid. ${ }^{2}$ Ten years ago, Leuschner $e a^{3}$ made the serendipitous observation that UDCA given for gall stone dissolution noticeably improved routine liver function tests in patients who also had chronic liver disease. Since then, there have been reports of potential benefits in a wide range of cholestatic and chronic inflammatory liver conditions, ${ }^{4}$ but most is known about the use of UDCA in primary biliary cirrhosis (PBC). In this article, we first discuss the pathogenesis of $\mathrm{PBC}$ and possible mechanisms of action of UDCA, and then review its clinical efficacy.
\end{abstract}

\section{Mechanisms of action of UDCA}

The pathophysiology of PBC can be considered as two processes. Firstly, immune damage directed at the intrahepatic bile ducts; and secondly, reduced bile flow (cholestasis) and retention of endogenous bile acids, which cause cytotoxic damage to the liver. ${ }^{45}$ There is accumulating evidence that UDCA may affect all these mechanisms.

\section{IMMUNOMODULATOR}

UDCA corrects some of the immune abnormalities previously described in PBC. Most prominent is the finding that UDCA reduces the aberrant expression of class 1 human leukocyte antigens (HLA 1) on hepatocytes. ${ }^{67}$ Although aberrant expression of major histocompatibility complexes is not a unique feature of $\mathrm{PBC},{ }^{8}$ they are important for recognition of hepatic tissue as targets by activated $\mathrm{T}$ lymphocytes. UDCA may also improve abnormalities in concentrations of circulating $\operatorname{IgM}^{9}{ }^{10}$ interferon $\gamma,{ }^{11}$ and activated T lymphocytes..$^{12}$ In vitro, the addition of UDCA can modulate the production of certain cytokines (interleukin 2 , interleukin 4 , and interleukin $\gamma$ ) from human mononuclear cells. ${ }^{13} 14$ UDCA is not the only bile acid that can affect immune function. The endogenous bile acid chenodeoxycholic acid can reduce in vitro cytokine production $^{15}$ and be immunosuppressive. ${ }^{16}$ Unfortunately, the importance of these findings is unclear as current understanding of the immune pathogenesis of PBC is limited. Taken together, these reports suggest that UDCA has some modulatory effects on immune function.

\section{BILE ACID RETENTION}

In a series of elegant physiological experiments on bile duct fistula rats, Kitani et al ${ }^{17}$ showed that hydrophobic bile acids reduce bile flow. Co-administration of UDCA and its conjugates protects bile flow. Furthermore, a bicarbonate rich hypercholeresis takes place that is associated with the cholehepatic circulation of unconjugated UDCA. ${ }^{18} 19$ We have recently used hepatoscintigraphy after intravenous injection of the $\gamma$ labelled bile acid ${ }^{75}$ selenium homocholic acid taurine $\left({ }^{75} \mathrm{SeHCAT}\right)$, and quantified a defect in hepatic bile acid excretion in PBC patients. UDCA increased hepatic bile acid excretion. ${ }^{20}$ Not only is hepatic bile acid excretion affected by UDCA but so is ileal reabsorption of endogenous bile acids. ${ }^{21} 22$ The net result of these effects on the enterohepatic bile acid circulation is alteration of the bile acid pool. The overall bile acid concentration rises by about $70 \% .^{23} 24$ This rise is accompanied by a rise from $3 \%$ to over $60 \%$ in the proportion of the bile acid pool made up by UDCA. ${ }^{23-25}$ The proportion of unconjugated bile acids remains small (about 5\%).

Whether the bile acid pool actually shifts towards hydrophilicity is uncertain. The proportion of cholic acid falls by about $40 \%{ }^{24-28}$ but the relative hydrophilicity of this bile acid is similar to UDCA. There are conflicting reports concerning the effects of treatment on the amount of chenodeoxycholic acid, the predominant retained hydrophobic bile acid. 252629

Although still controversial, a shift towards hydrophilicity is an attractive mechanism for the action of UDCA in PBC. Relatively hydrophobic bile acids such as chenodeoxycholic acid and deoxycholic acid are more damaging to cells than hydrophilic bile acids such as UDCA. Therefore enrichment of the bile acid pool with hydrophilic UDCA at the expense of hydrophobic endogenous bile acids would make it less toxic.

\section{CYTOPROTECTION}

There is also some evidence that UDCA has direct cytoprotective effects. In vitro, incubation of hepatocytes with chenodeoxycholic acid leads to leakage of cellular enzymes. The addition of UDCA to the incubation 
mixture reduces this damage. ${ }^{30} 31$ Hydrophobic bile acids certainly damage hepatocyte mitochondrial energy production $^{32}$ and there is data from ourselves and others that UDCA protects energy production. ${ }^{33} 34$

This cytoprotective effect is probably related to the ability of UDCA to protect membranes. ${ }^{35}$ Heuman et al ${ }^{36}$ found that UDCA reduces hydrophobic bile acid disruption of artificially synthesised membranes. We found in vitro, that UDCA reduces the amount of cholesterol and phospholipid solubilised by chenodeoxycholic acid from isolated human hepatocyte bile canalicular membrane. ${ }^{37}$ Two mechanisms may be related to this phenomenon. Firstly, there is evidence that UDCA can interact with more hydrophobic bile acids and thereby reduce their polarity. Secondly UDCA can bind to membranes and affect their fluidity and stability. ${ }^{38}$

\section{Clinical efficacy of UDCA in PBC}

Fisher and Paradine in $1986^{39}$ were the first to report the use of UDCA in PBC. All 10 patients had improved serum liver enzymes. Several small open studies reporting remarkably uniform results followed. ${ }^{4}$ These encouraging findings were followed by four large multicentre doubleblind, randomised, placebo controlled trials of UDCA in PBC.

\section{DOUBLE BLIND PLACEBO CONTROLLED DATA}

All four trials were large (150-220 patients each), had a study period of two years, and reported broadly similar results. ${ }^{9} 102340$ Serum bilirubin and liver enzymes significantly improved and this improvement was sustained for two years. Improvement in IgM was observed in three trials ${ }^{91023}$ and improvement in AMA in one. ${ }^{9}$ Clinical features such as pruritus and fatigue improved significantly in only one trial. ${ }^{9}$ None of these trials reported an overall improvement in histological disease stage (defined using established criteria). ${ }^{41}$ In the trials in which specific histological criteria were examined, however, improvements in certain parameters such as hepatocellular ballooning, bile duct paucity, ductular proliferation, inflammatory cell infiltration, necrosis, and cholestasis were reported. 92340 Three of these trials used 'treatment failure', a composite end point including parameters such as biochemical deterioration, development of complications, withdrawal from the study, liver transplantation, and death. ${ }^{9} 1039$ In two of these three trials, there were significantly fewer treatment failures on UDCA compared with placebo. Two of the trials assessed the effect of UDCA on the Mayo risk score, ${ }^{42}$ a predictive score based on bilirubin, albumin, age, prothrombin time, and oedema. ${ }^{9}{ }^{10}$ In both, the Mayo risk score improved on UDCA. Patients were stratified according to early or advanced disease (depending on serum bilirubin concentrations) in two trials, ${ }^{1040}$ but the effect of disease stage on efficacy of UDCA was unclear.

Overall, the results of these trials were encouraging but did not provide conclusive results. Certain surrogate end points improved but their significance remain to be proved. As bilirubin is an independent prognostic marker in untreated PBC, ${ }^{43}$ UDCA induced improvement in bilirubin was thought to suggest improved survival. This conclusion may not be valid as the prognostic value of a fall in bilirubin on UDCA therapy remains to be proved. Alkaline phosphatase, $\gamma$ glutamyl transpeptidase, and serum transaminases improve on average by $50 \%$. Although these results are encouraging, their long term significance must remain speculative. Improvements in serum IgM and AMA suggest that UDCA may be having some immunomodulatory effect, but the role of both IgM and AMA on the pathophysiology of PBC is not clearly understood. The use of a composite end point of 'treatment failure' may be misleading: not only are equal weights given to different reasons for failure but their use has not been validated. There are also problems with the Mayo risk score as a trial end point. The model is a valid means for predicting outcome in untreated PBC but its validity in evaluating the effects of treatment on prognosis has not been tested.

The effects on important parameters such as clinical symptoms and histology remain controversial. Both are difficult to assess. Clinical end points such as pruritus and fatigue are subjective, non-specific, and vague and are strongly influenced by placebo effect. ${ }^{23}$ Changes in the liver in PBC are patchy and liver biopsies are subject to problems of sampling error. ${ }^{44}$

There is an inherent danger of being over optimistic in extrapolating possible long term clinical benefit from improvements in surrogate end points such as liver function tests. What do the double blind placebo control trials tell us about long term outcome? Two long term end points of mortality and the need for liver transplantation have been used. Although both are lower on UDCA compared with placebo, statistical significance was not reached in any of the trials. The sample size is likely to be inadequate for assessing these end points. A combined analysis of the raw data from the French, ${ }^{9}$ American, ${ }^{10}$ and Canadian ${ }^{23}$ trials has been carried out and published in preliminary form. ${ }^{45}$ UDCA treatment was found to improve survival free of transplant (defined as time to transplant or death without transplant) when compared with placebo.

\section{LONG TERM FOLLOW UP STUDIES}

Completely reliable data on the longterm benefits of UDCA would ideally come from a large (eg, 1000 patients) longterm (eg, 10 years) double blind placebo controlled trial, but logistic difficulties prevent such a study. There is, however, some longer term survival data from open treatment studies. Two groups have reported sustained improvement in liver function tests after 6.5 years and improved survival compared to historical controls. ${ }^{4647}$ Recently Poupon et al ${ }^{48}$ published the four year follow up data on their original cohort of 146 patients. using the endpoint of 'death or liver transplantation', patients treated on UDCA for four years fared significantly better than those who had initially received two years of placebo followed by two years of UDCA. There are difficulties in using liver transplantation as an endpoint as these decisions are not based on fixed or fully objective criteria.

\section{BETTER SURROGATE END POINTS}

In a recent study we determined hepatic excretory function by measuring the plasma disappearance of injected ${ }^{99 \mathrm{~m}}$ TcHIDA, before and during three months' treatment. There was significant improvement in the UDCA group compared with the placebo group. ${ }^{49}$ Other groups have assessed the effects of UDCA using dynamic liver function tests (bromosulpthalein clearance test, aminopyrine breath tests, galactose excretion test) with conflicting results. ${ }^{50-52}$ Floreani et $\mathrm{al}^{53}$ detected no change in serum markers of fibrosis (serum hyaluronate, type III procollagen amino propeptide) in PBC patients after two years of UDCA.

\section{Future developments}

The possibility that the efficacy of UDCA may be enhanced using combination therapy directed against immunological damage and fibrosis has stimulated some 
interest. Several double blind prospective trials are in progress and there have been several early reports. Colchicine is a drug that affects collagen synthesis and has anti-inflammatory properties. So far, combination therapy of UDCA with colchicine does not seem to confer much additional benefit. Improvement in liver enzymes is small and there has been no increase in symptomatic benefit or histological improvement. ${ }^{545}$ There are preliminary reports of additional improvements in liver enzymes when either methotrexate or corticosteroids are used in combination with UDCA. ${ }^{56} 57$ Unlike UDCA, these drugs have potentially severe side effects. Methotrexate can cause interstitial pneumonitis and corticosteroids have severe deleterious effects on the bones of these patients who already have low bone mineral density. ${ }^{58}$ It is unlikely that they will be popular as agents for long term use.

Developments in molecular biology have increased our understanding of general immune mechanisms as well as specific immunological defects in PBC. Of recent interest is the role of adhesion molecules in a variety of liver diseases. ${ }^{59}$ These molecules bind to specific ligands and control the adhesion of lymphocytes to targets of immune damage. There is upregulation of adhesion molecules in PBC. ${ }^{60-62}$ The use of recombinant molecules to block adhesion reactions are currently being explored in a variety of diseases and may potentially be useful in PBC. ${ }^{63}$ There have also been advances in understanding the central immunological abnormality in PBC. The antigen to M2 antibody, the characteristic autoimmune antibody in PBC has been clearly identified. ${ }^{64}$ Components of this antigen has been shown to stimulate $\mathrm{T}$ lymphocytes from PBC patients ${ }^{65}$ and to be expressed on bile duct cells. ${ }^{6667}$ It is hoped that these advances in understanding will lead to development of molecular therapies more effective than UDCA, but these are still some years away.

\section{Conclusion}

UDCA has immunomodulatory action, improves hepatic excretion, is less toxic than endogenous hydrophobic bile acids, and is cytoprotective. In PBC, there is sustained improvement in serum bilirubin and routine liver enzymes. Whether it can increase survival is unknown. Compared with other previously assessed treatments, however, UDCA is efficacious, non-toxic, well tolerated, and suitable for long term use. Except for those with incipient liver failure who should be considered for liver transplantation, PBC patients should be treated with UDCA.

A G LIM R P JAZRAWI T C NORTHFIELD

Division of Biochemical Medicine,

St George's Hospital Medical School,

London SW17 ORE

1 Kitani K. Hepatoprotective effect of ursodeoxycholate in experimental animals. In: Paumgartner G, Stiehl A, Barbara L, Roda E, eds. Strategies for the treatment of hepatobiliary diseases. Dordrecht: Kluwer Academic Publishers, 1990: 43-56.

2 Matschiner JT. Naturally occurring bile acids and alcohols and their origins. In: Kritchevsky D, Nair PP, eds. The bile acids. New York: Plenum Press, 1971: 11-46.

3 Leuschner U, Leuschner M, Sieratzki J, Kurtz W, Hubner K. Gallstone dissolution with ursodeoxycholic acid in patients with chronic active hepatitis and two year follow up: a pilot study. Dig Dis Sci 1985; 30: $642-9$

4 De Caestecker JS, Jazrawi RP, Petroni ML, Northfield TC. Ursodeoxycholic acid in chronic liver disease. Gut 1991; 31: 1061-5.

5 Hafmann AF, Popper H. Ursodeoxycholic acid for primary biliary cirrhosis. Lancet 1987; ii: $398-9$.

6 Calmus Y, Gane P, Rouger P, Poupon R. Hepatic expression of class I and class II histocompatibility complex molecules in primary biliary cirrhosis: effect of ursodeoxycholic acid. Hepatology 1990; 11: 12-5.

7 Terasaki S, Nakanuma Y, Ogino H, Unoura $\mathbf{M}$, Kobayashi $\mathbf{K}$ Hepatocellular and biliary expression of HLA antigens in primary biliary cirrhosis before and after ursodeoxycholic acid therapy. Am $\mathcal{f}$ Gastroenterol 1991; 86: 1194-9.
8 Calmus Y, Arvieux C, Gane P, Boucher E, Nordlinger B, Rouger P, Poupon $R$. Cholestasis induces major histocompatibility complex class I expression in hepatocytes. Gastroenterology 1992; 102: 1371-7.

9 Poupon RE, Balkau B, Eschwege E, Poupon R, and the UDCA study group. A multicenter double blind trial of ursodiol for the treatment of primary biliary cirrhosis. N Engl f Med 1991; 324: 1548-54.

10 Lindor KD, Dickson ER, Baldus WP, Jorgensen RA, Ludwig J, Murtagh $\mathrm{PA}$, et al. Ursodeoxycholic acid in the treatment of primary biliary PA, et al. Ursodeoxycholic acid in the treat

11 Ogino H, Unoura M, Saeki R, Terasaki S, Kawai H, Matushita E, et al. Effect of ursodeoxycholic acid treatment on interferon-g synthesis in patients with primary biliary cirrhosis. Hepatology 1992; 16: 193A

12 Kurktschiev D, Subat S, Adler D, Schentke K-U. Immunomodulating effect of ursodeoxycholic acid therapy in patients with primary biliary cirrhosis. f Hepatol 1993; 18: 373-7.

13 Yoshikawa M, Tsujii T, Matsumara K, Yamao J, Matsumura Y, Kubo R, et al. Immunomodulatory effects of ursodeoxycholic acid on immune responses. Hepatology 1992; 16: 358-64.

14 Lacaille F, Paradis K. The immunosuppressive effect of ursodeoxycholic acid: a comparative in vitro study on human peripheral blood mononuclear cells. Hepatology 1993; 18: 165-72.

15 Calmus Y, Guechot J, Podevin P, Bonnefis M-T, Giboudeau J, Poupon R. Differential effects of chenodeoxycholic acid and ursodeoxycholic acids on interleukin 1 , interleukin 6 and tumour necrosis factor- $\alpha$ production by monocytes. Hepatology 1992; 16: 719-23.

16 Calmus Y, Weill B, Ozier Y, Chereau C, Houssin D, Poupon R. Immunosuppressive properties of chenodeoxycholic and ursodeoxycholic acids in the mouse. Gastroenterology 1992; 103: 617-21.

17 Kitani K, Ohta M, Kanai S. Tauroursodeoxycholate prevents biliary protein excretion induced by other bile salts in the rat. Am f Physiol 1985; 248: G407-8.

18 Dumont M, Erlinger S, Uchman S. Hypercholeresis induced by ursodeoxycholic acid and 7-ketolithocholic acid in the rat: possible role of bicarbonate transport. Gastroenterology 1980; 79: 82-9.

19 Erlinger S. Hypercholoretic bile acids: a clue to the mechanism? Hepatology 1990; 11: 888-90.

20 Jazrawi RP, De Caestecker JS, Goggin PM, Britten AJ, Joseph AEA, Maxwell JD, et al. Kinetics of hepatic handling in cholestatic liver disease: effect of ursodeoxycholic acid. Gastroenterology 1993; 106: 134-42.

21 Marteau P, Chazouilleres O, Myara A, Jian R, Rambaud J-C, Poupon R. Effect of chronic administration of endogenous bile acids in man. Hepatology 1990; 12: 1206-8.

22 Stiehl A, Raedsch R, Rudolph G. Acute effects of ursodeoxycholic and chenodeoxycholic acid on the small intestinal absorption of bile acids. Gastroenterology 1990; 98: 424-8.

23 Heathcote EJ, Cauch-Dudek K, Walker V, Bailey RJ, Blendis LM, Ghent $\mathrm{CN}$, et al. The Canadian multicentre double blind randomized controlled trial of ursodeoxycholic acid in primary biliary cirrhosis. Hepatology 1994; 19: $1149-56$.

24 Stiehl A, Rudolph G, Raedsch R, Moller B, Hoff U, Lotterer E, et al. Ursodeoxycholic acid-induced changes of plasma and urinary bile acids in patients with primary biliary cirrhosis. Hepatology 1990; 12: 492-7.

25 Poupon RE, Chretien Y, Poupon , Paumgartner G. Serum bile acids in primary biliary cirrhosis: effect of ursodeoxycholic acid. Hepatology 1993, 17: 599-604.

26 Crosignani A, Podda M, Battezzati PM, Bertolini E, Zuin M, Watson D, Setchell KDR. Changes in bile acid composition in patients with primary biliary cirrhosis induced by ursodeoxycholic acid administration. Hepatology 1991; 14: 1000-7.

27 Batta AK, Arora R, Salen G, Tint GS, Eskreis D, Katz S. Characterization of serum and urinary bile acids in patients with primary biliary cirrhosis. of serum and urinary bile acids

28 Mazzella G, Parini P, Bazzoli F, Villanova N, Festi D, Aldini R, et al. Ursodeoxycholic administration on bile acid metabolism in patients with early stages of primary biliary cirrhosis. Dig Dis Sci 1993; 38: 896-902.

29 Beuers U, Spengler U, Zwiebel FM, Pauletzki J, Fischer S, Paumgartner G. Effect of ursodeoxycholic acid on the kinetics of the major hydrophobic bile acids in health and in chronic cholestatic liver disease. Hepatology 1992; 15: 603-8.

30 Heuman DM, Pandak WM, Hylemon PH, Vlahcevic ZR. Conjugates of ursodeoxycholate protect against cytotoxicity of more hydrophobic bile salts: In vitro studies in rat hepatocytes and human erythrocytes. salts: In vitro studies in

31 Galle PR, Theilmann L, Raedsch R, Otto G, Stiehl A. Ursodeoxycholate reduces hepatotoxicity of bile salts in primary human hepatocytes. Hepatology 1990; 12: 486-91.

32 Krahenbuhl S, Talos C, Fischer S, Reichen J. Toxicity of bile acids on the electron transport chain of isolated rat liver mitochondria. Hepatology 1993; 19: 471-9.

33 Lim AG, Ahmed HA, Jazrawi RP, Northfield TC. Effects of bile acids on human hepatic mitochondria. Eur $\mathcal{f}$ Gastroenterol Hepatol 1994; 6: 1157-63.

34 Krahenbuhl S, Talos C, Reichen J. Mitochondrial toxicity and partial reversal by ursodeoxycholate. Hepatology 1992; 16: 156.

35 Heuman D. Hepatoprotective properties of ursodeoxycholic acid. Gastroenterology 1993; 104: 1865-70.

36 Heuman DM, Bajaj R. Ursodeoxycholate conjugates protect against disruption of cholesterol-rich membranes by bile salts. Gastroenterology 1994; 106: $1333-41$.

37 Lim AG, Ahmed HA, Jazrawi RP, Northfield TC. The effect of ursodeoxycholic acid and chenodeoxycholic acid on human hepatocyte and erythrocyte membranes. gut 1993; 34: S45.

38 Guldutuna S, Zimmer G, Imhof M, Bhatti S, Tiangeng Y, Leuschner U. Molecular aspects of membrane stabilisation by ursodeoxycholate. Hepatology 1993; 104: 1736-44.

39 Fisher MM, Paradine ME. Influence of ursodeoxycholic acid on biochemical parameters in cholestatic liver disease. Gastroenterology 1986; 90: 1725 .

40 Combes B, Carithers RL, Maddrey WC, Munoz SJ, Mcdonald MF, GarciaTsao G, et al. A randomized, double blind, placebo controlled trial of ursodeoxycholic acid (UDCA) in primary biliary cirrhosis. Hepatology 1993; 18: $175 \mathrm{~A}$.

41 Ludwig J, Dickson ER, McDonald GSA. Staging of non-suppurrative 
destructive cholangitis (syndrome of primary biliary cirrhosis). Virchows Arch A 1978; 379: 103-12.

42 Dickson ER, Grambsch PM, Fleming TR, Fisher LD, Langworthy A Prognosis in primary biliary cirrhosis: a model of decision making. Hepatology 1989; 10: 1-7.

43 Shapiro JM, Smith H, Schaffner F. Serum bilirubin: a prognostic factor in primary biliary cirrhosis. Gut 1979; 20: 137-40.

44 Portmann B, Macsween RNM. Diseases of the intrahepatic bile ducts. In Macsween RNM, Anthony P, Scheuer P, eds. Pathology of the liver. 2nd ed. London: Churchill Livingstone, 1987: 424-53.

45 Heathcote EJ, Lindor KD, Poupon R, Cauch-Dudek K, Dickson ER, Trout $\mathrm{R}$, et al. Combined analysis of French, American and Canadian randomised controlled trials of ursodeoxycholic acid therapy in primary biliary cirrhosis. Gastroenterology 1995; 108: A1082.

46 Leuschner U, Guldutuna S, Imhof M, Leuschner M. Ursodeoxycholic acid does not cure primary biliary cirrhosis but prolongs survival. Results of a does not cure primary biliary cirrhosis but prolo

47 Bateson MC, Gedling P. Effect of ursodeoxycholic acid on survival in primary biliary cirrhosis. Gut 1994; 35: S20.

48 Poupon RE, Poupon R, Balkau B, and the UDCA study group. Ursodiol for the longterm treatment of primary biliary cirrhosis. N Engl f Med 1994; 330: 1342-7.

49 Lim AG, Jazrawi RP, Maxwell JD, Northfield TC. Ursodeoxycholic acid improves hepatic excretion in primary biliary cirrhosis. Gut 1994; 35: S11.

50 Poupon R, Chretien Y, Ballet F, Calmus Y, Darnis F. Is ursodeoxycholic acid an effective treatment for primary biliary cirrhosis. Lancet 1987; i: 834-6.

51 Lotterer E, Stiehl A, Raedsch R, Foelsch UR, Bircher R. Ursodeoxycholic acid in primary biliary cirrhosis: no evidence for toxicity in the stages I to III. $\mathcal{F}$ Hepatol 1990; 10: 284-90.

52 Huet PM, Willems B, Huet J, Poupon R. Effects of ursodeoxycholic acid on hepatic function and portal hypertension in primary biliary cirrhosis. In: hepatic function and portal hypertension in primary biliary cirrhosis. In:
Proceedings of the XIIth International Bile Acid Meeting. Basel, Switzerland: Falk Symposium no 68, 1992: 118.

53 Floreani A, Zappala F, Mazzetto M, Naccarato R, Plebani M, Charamonte $M$. Different response to ursodeoxycholic acid (UDCA) in primary biliary cirrhosis according to severity of disease. Dig Dis Sci 1994; 39: 9-14.

54 Podda M, Italian Multicentre Group for the Study of UDCA in PBC. Long term effects of the administration of ursodeoxycholic acid alone or with colchicine in patients with primary biliary cirrhosis. A double blind multicentre trial. In: Proceedings of the XIIth International Bile Acid Meeting. Basle, Switzerland: Falk Symposium no 68, 1992: 50-1.
55 Raedsch R, Stiehl A, Rudi J, Schlenker T, Gerteis C, Kommerell B, biliary cirrhosis: efficacy, pharmacology and urso - colchicine drug interbiliary cirrhosis: efficacy, pharmacology and urso - colchicine drug inter-
actions. In: Proceedings of the XIIth International Bile Acid Meeting. Basle, actions. In: Proceedings of the XIIth International Bite

56 Kaplan MM. The therapeutic effects of ursodiol and methotrexate are additive and well tolerated in primary biliary cirrhosis. Hepatology 1992; 16: $92 \mathrm{~A}$.

57 Wolfhagen FHJ, van Buuren HR, Schalm SW. Combined treatment with ursodeoxycholic acid and prednisone in primary biliary cirrhosis. Neth $\mathcal{f}$ Med 1994; 44: 84-90.

58 Kaplan MM. Primary biliary cirrhosis - a first step in prolonging survival. N Engl f Med 1994; 330: 1386-7.

59 Adams DH, Shaw S. Leucocyte-endothelial interactions and regulation of leucocyte migration. Lancet 1994; 343: 831-6.

60 Adams DH, Hubscher SG, Shaw J, et al. Increased expression of ICAM-1 on bile ducts in primary biliary cirrhosis and primary sclerosing cholangitis. Hepatology 1991; 14: 426-31.

61 Lim AG, Jazrawi RP, Levy JH, Douds AC, Zuin M, Maxwell JD, Northfield TC. Soluble intercellular adhesion molecule 1 in primary biliary cirrhosis: relationship with disease stage, immune activity and cholestasis. Hepatology 1994; 20: 882-8.

$62 \mathrm{Lim}$ AG, Jazrawi RP, Levy JH, Petroni ML, Douds AC, Maxwell JD, Northfield TC. Soluble E-selectin and vascular cell adhesion molecule-1 (VCAM-1) in primary biliary cirrhosis. $\mathcal{f}$ Hepatol 1995; 22: 416-22.

63 de Vries RPP, Kolb H, Martin S. Soluble forms of ICAM-1 in insulin dependent diabetes mellitus. Lancet 1994; 343: 1590-92.

64 Fussey SP, Guet JR, James OF, Bassendine MF, Yeaman SJ. Identification and analysis of the major M2 autoantigens in primary biliary cirrhosis. Proc Natl Acad Sci USA 1988; 85: 8564-8.

65 Jones DEJ, Palmer JM, Yeaman SJ, Diamond AG, Bassendine MF. T-cell responses to human pyruvate dehydrogenase complex and its components responses to human pyruvate dehydrogenase complex and its

66 Van de Water J, Turchany J, Leung PC, Lake J, Munoz S, Surh CD, et al. Molecular mimicry in primary biliary cirrhosis. $\mathcal{f}$ Clin Invest 1993; 91: 2653-64.

67 Tsuneyama K, Van de Water J, Leung PSC, Sanghoon C, Nakanuma Y, Kaplan $M$, et al. Abnormal expression of the $E_{2}$ component of the pyruvate dehydrogenase complex on the luminal surface of biliary epithelium occurs before major histocompatibility complex class II and BB1/B7 expression. Hepatology 1995; 21: 1031-7. 